\title{
Preparation and Mechanical Properties of Continuous Carbon Nanotube Networks Modified $\mathrm{C}_{\mathrm{f}} / \mathrm{SiC}$ Composite
}

\author{
Lei Wang, Feng Hou, Xin Wang, Jiachen Liu, and Anran Guo \\ Key Laboratory of Advanced Ceramics and Machining Technology of Ministry of Education, Tianjin University, Tianjin 300072, China \\ Correspondence should be addressed to Feng Hou; houf@tju.edu.cn
}

Received 30 March 2015; Revised 17 May 2015; Accepted 18 May 2015

Academic Editor: Antônio G. B. de Lima

Copyright (C) 2015 Lei Wang et al. This is an open access article distributed under the Creative Commons Attribution License, which permits unrestricted use, distribution, and reproduction in any medium, provided the original work is properly cited.

Continuous carbon nanotube (CNT) networks were formed in $\mathrm{C}_{\mathrm{f}} / \mathrm{SiC}$ composites via freeze-drying method. Composites were fabricated by precursor infiltration and pyrolysis (PIP) process afterwards. The different distribution morphologies of CNTs in the preforms originating from the different CNT contents were analyzed while the influence of the distribution of CNTs was discussed in detail. Compared to composites without CNTs, the interfacial shear strength (ILSS) and the flexural strength of $\mathrm{C}_{\mathrm{f}} / 1 \% \mathrm{CNTs} / \mathrm{SiC}$ were increased by $31 \%$ and $27 \%$, respectively, but the values of $\mathrm{C}_{\mathrm{f}} / 2.5 \% \mathrm{CNTs} / \mathrm{SiC}$ decreased as a result of lots of defects caused by excess CNTs. With the analysis of ILSS, the flexural strengths, and the fracture morphologies, CNTs effectively improved the weak interfacial strength between T700SC carbon fibers and $\mathrm{SiC}$ matrix.

\section{Introduction}

Continuous carbon fiber reinforced ceramic matrix composites (CFCMCs) have many advantages, such as low density, high strength, high fracture toughness, and oxidation resistance, and are the most promising candidates for applications in harsh conditions [1-5]. Currently, $\mathrm{C}_{\mathrm{f}} / \mathrm{SiC}$ composites are extensively studied and have been mainly applied to engine combustion chamber, aerospace heat shield, and friction materials $[6,7]$. However, in the laminated $\mathrm{C}_{\mathrm{f}} / \mathrm{SiC}$ composites, the region in interlaminar matrix and among fiber bundles is still weak and makes little contribution to the strength and toughness of the $\mathrm{C}_{\mathrm{f}} / \mathrm{SiC}$ composites [8], inhibiting the applications.

The nanoscale reinforcement of CNTs, possessing excellent mechanical, thermal, and electronic properties [9-11], are applied in $\mathrm{C}_{\mathrm{f}} / \mathrm{SiC}$ composites to overcome the abovementioned weak points. To improve the matrix, CNTs are directly dispersed into organic precursors before composites are prepared via PIP process $[12,13]$. Yet nonuniform dispersion and low loading fraction of CNTs limit its application. To alleviate the agglomeration of CNTs, grafting CNTs on fibers via chemical vapor deposition (CVD) process is also developed [14-17]. The interfacial strength between fibers and $\mathrm{SiC}$ matrix can be improved effectively. However, the approach has its inherent shortcomings, such as the high fabricating temperature and the difficulties in processing large panels. Besides, the side reaction during CVD process would degrade the fiber strength [18].

Previously, freeze-drying technique has been adopted to build continuous CNT networks in unidirectional [19, 20] and two-dimensional [21] carbon fibers/epoxy resin laminated composites. Using the freeze-drying method, continuous and uniform CNT networks are grafted on fibers in one bundle while discontinuous CNT networks (existing in the form of sheets) are formed in the space between bundles and the interlaminar region. The novel CNT spatial structures can not only form suitable interfacial strength between fibers and $\mathrm{SiC}$ matrix, but also improve the performance in interlaminar matrix partially via CNT sheets. On the other hand, the approach is processed in a mild condition and thus can maintain full performance of pristine carbon fibers, such as fiber strength and surface integrity. Moreover, the morphologies of CNT structure can be easily controlled by adjusting the freezing parameters [22] and the content of CNTs $[23,24]$, enabling designing the spatial structure of CNTs effectively. 
In the present work, we try to use the method to prepare continuous $\mathrm{CNT}$ networks in $\mathrm{C}_{\mathrm{f}} / \mathrm{SiC}$ composites to overcome the shortcomings. The influence of CNT contents on the morphologies of CNT networks is studied. And the mechanism of improving the mechanical properties of the composites is discussed in detail.

\section{Experimental}

2.1. Materials. T700SC unidirectional carbon fiber cloths with yarns of 12000-filament count (Toray, Japan), of which single filament diameter, density, and tensile strength are $7 \mu \mathrm{m}, 1.80 \mathrm{~g} / \mathrm{cm}^{3}$, and $4.9 \mathrm{GPa}$, respectively, were used as reinforcement. Polycarbosilane (PCS), with molecular weight of $\sim 1400$ and the soften point of $210^{\circ} \mathrm{C}$ (Suzhou Cerafil Co., Ltd., China), and divinylbenzene (DVB) (Aladdin) were used as precursor. Commercial aqueous CNT slurry with the concentration of $5 \mathrm{wt} \%$ was purchased from Shenzhen Nanotech Port Co., Ltd., China.

2.2. Preparation of $C_{f} / C N T s / S i C$ Composites. The $\mathrm{C}_{\mathrm{f}} / \mathrm{CNTs}$ preforms and the final composites were prepared as follows. (1) CNT aqueous solution with different concentrations of $1 \mathrm{wt} \%$ and $2.5 \mathrm{wt} \%$ was prepared by diluting commercial CNT slurry with deionized water. (2) The unidirectional carbon fiber fabrics were made by pressing 11 layers of $\mathrm{C}_{\mathrm{f}}$ cloth along the same direction to a thickness of $4 \mathrm{~mm}$. The fiber volume fraction of the fabrics was $\sim 45 \%$. (3) The carbon fiber fabrics were impregnated with diluted CNT solution under vacuum for $0.5 \mathrm{~h}$, dipped into liquid nitrogen rapidly, and left to stand for $8 \mathrm{~h}$. Then, the $\mathrm{C}_{\mathrm{f}} / \mathrm{CNT}$ s preforms were prepared by freeze-drying for $72 \mathrm{~h}$ in the freeze-drier. And the freeze-drier (model: FD-1-50), with high ultimate vacuum $(<20 \mathrm{~Pa})$ and low operating temperature $\left(<-55^{\circ} \mathrm{C}\right)$, was made by Beijing Boyikang Co., Ltd. (4) The $\mathrm{C}_{\mathrm{f}} / \mathrm{CNT}$ s preforms were impregnated with the precursor solution, consisting of PCS and DVB with the mass ratio of 1:0.4, through a similar resin transfer moulding (RTM) process before transferring to an oven, and cured at $120^{\circ} \mathrm{C}$ for $6 \mathrm{~h}$. (5) The cured samples were pyrolyzed at $1000^{\circ} \mathrm{C}$ for $2 \mathrm{~h}$ in argon atmosphere, with the heating rate of $10^{\circ} \mathrm{C} / \mathrm{min}$. To acquire dense composites, 7 cycles of PIP were performed.

2.3. Characterization. Archimedes's method with kerosene as immersing liquid was used to get the densities and porosities of the composites. Transmission Electron Microscope (TEM) (JEM100CXII from JEOL) was used to observe the microstructure of CNTs. Scanning Electron Microscope (SEM) (S4800 from Hitachi Corporation in Japan) was used to study morphologies of dispersion state of CNTs in the preforms and fracture morphologies of the composites after test. The flexural strength was carried out using a threepoint bending test on specimens with the size of $40 \times 4$ $\times 2 \mathrm{~mm}$ (length $\times$ width $\times$ height), a $32 \mathrm{~mm}$ span, and a $0.5 \mathrm{~mm} / \mathrm{min}$ cross-head speed. ILSS tests followed ASTM D2344 guidelines. Five specimens were tested for each set of conditions.

\section{Results and Discussion}

3.1. Morphologies of $C_{f} / C N T s$ Preforms after Freeze-Drying. The morphology of the as-received carbon fiber cloth is shown in Figure 1(a). The spacing between fibers in intrabundle region ranges from a few hundred nanometers to several micrometers, with the diameter of $7 \mu \mathrm{m}$. And the surface of T700SC carbon fibers is smooth, contrary to that of T300 where there are grooves [25]. CNT slurry was dispersed into deionized water by ultrasonication ( $30 \mathrm{~min}$ ) for TEM observation on pristine CNTs. The result (Figure 1(b)) indicates that the as-used CNTs are multiwalled with the diameter of $20 \mathrm{~nm}$ and the lattice fringe of CNTs is not clear, implying poor crystallinity.

The dispersion state of $1 \mathrm{wt} \%$ CNTs in the preform after freeze-drying is observed. As seen in Figure 1(c), the surface of carbon fibers is rough, rather different from that of pristine fibers, indicating that CNTs are effectively grafted on fibers. The change of the diameter of the fibers is not obvious, implying a thin CNT layer grafted on $\mathrm{C}_{\mathrm{f}}$. Although the CNT layers were grafted on the fibers uniformly, the continuity of the CNT networks between fibers in one bundle was affected by the spacing between fibers, resulting from the mechanism of freeze-drying within confined space [20]. It appears that CNT networks trend to be continuous when the spacing is merely several hundred nanometers while discontinuous CNT networks can be found when the spacing spans up to several micrometers. And the former was predominant on the whole. Discontinuous parallel CNT sheets with the bottom width of $1 \mu \mathrm{m}$ were formed from the simultaneous rejection by two adjacent ices crystals [26]. The CNT morphology contrasted with the one prepared by CVD method $[14,17]$. The magnifying image (Figure $1(\mathrm{~d})$ ) reveals that the twisted CNTs interact with each other in an entangled state, with the length of several micrometers and the diameters of $\sim 30 \mathrm{~nm}$, well-matched to the TEM results. CNTs are uniformly grafted on fibers while the space between fibers fills with porous CNT networks. Nanopores of $\sim 200 \mathrm{~nm}$ provide channels for precursor impregnation, together with nonclosed structures of CNT sheets.

As shown in Figure 1(e), the diameter of the fibers increases significantly when the content of CNTs increases to $2.5 \mathrm{wt} \%$. By contrast, the thickness of $\mathrm{CNT}$ layer is up to $500 \mathrm{~nm}$, far greater than that of $1 \mathrm{wt} \%$. The CNT networks between fibers trend to be more continuous because more CNTs fill the space, companying with the formation of cell structures. And the novel cell structure is nearly closed with the bottom width of $\sim 4 \mu \mathrm{m}$, four times thicker than that of CNT sheets in $\mathrm{C}_{\mathrm{f}} / 1 \% \mathrm{CNT}$ preform. The cell CNT structure arose from CNT sheets that grew up and connected to each other due to the increment of CNTs. The occupied state of the space between fibers is observed in Figure 1(f) and dense CNT networks fill. Nevertheless, nearly closed cell structure and dense CNT networks might be disadvantageous to the process of precursor impregnation and generate defects in the as-fabricated $\mathrm{C}_{\mathrm{f}} / \mathrm{SiC}$ composites in virtue of strong diffusion resistance to precursor solution. 


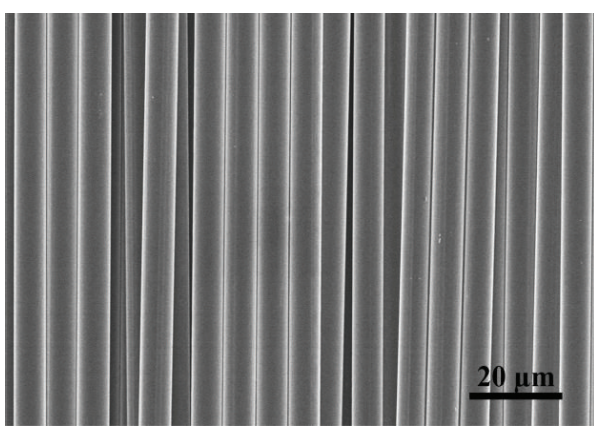

(a)

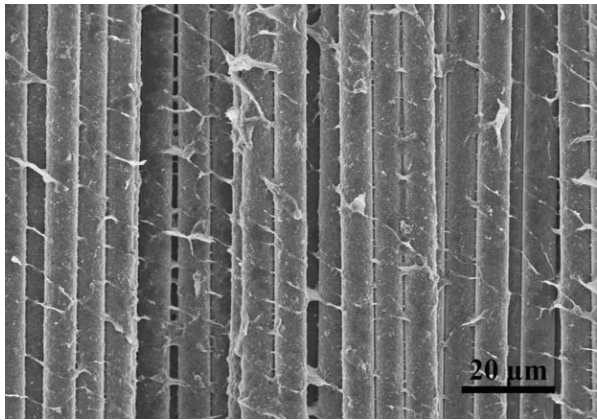

(c)

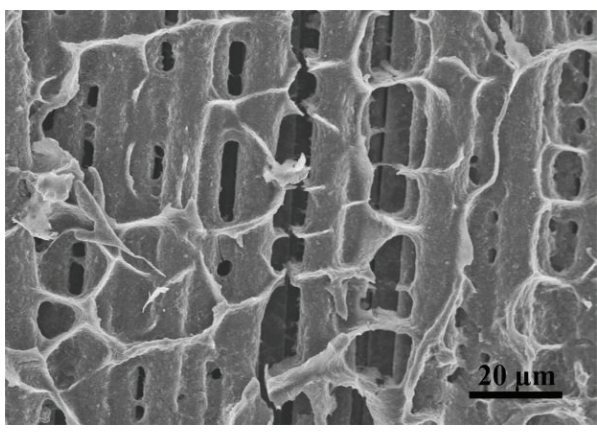

(e)

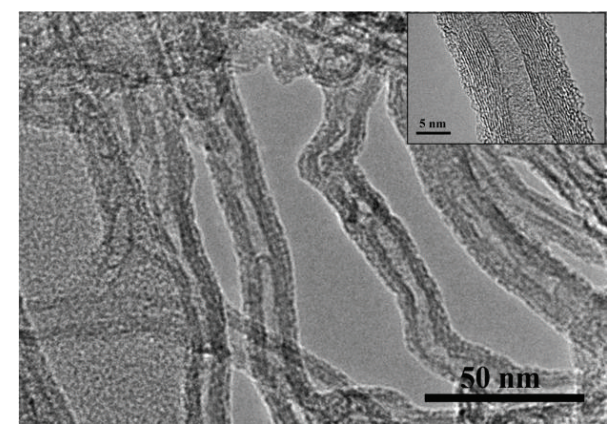

(b)

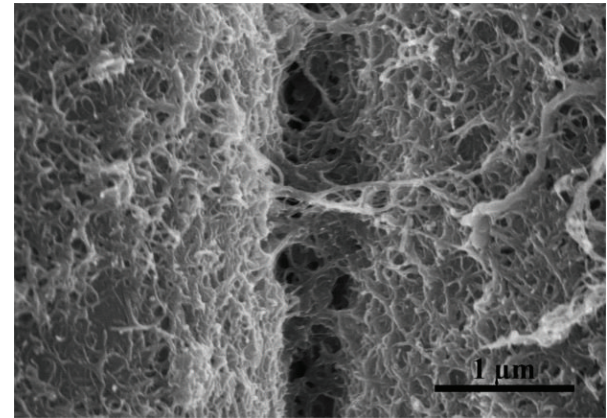

(d)

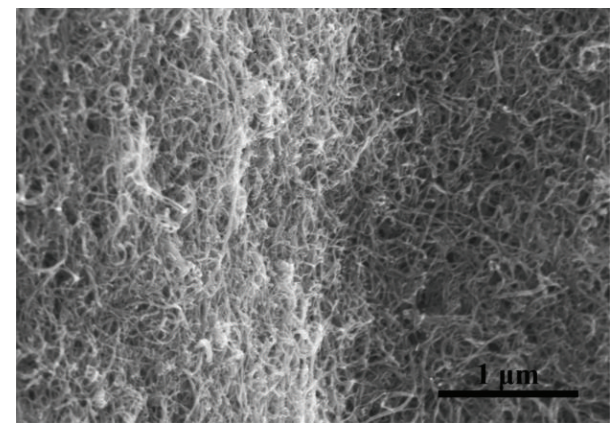

(f)

FIGURE 1: (a) SEM micrograph of as-received carbon fibers, (b) TEM image of pristine multiwalled CNTs, (c) SEM image of the distribution of CNTs in the preform with the CNT content of $1 \mathrm{wt} \%$, (d) SEM image of CNT networks of $1 \mathrm{wt} \%$ between fibers in one fiber bundle, (e) the distribution of CNTs in the preform with the CNT content of $2.5 \mathrm{wt} \%$, and (f) SEM image of CNT networks of $2.5 \mathrm{wt} \%$ between fibers in one fiber bundle.

3.2. The Influence of CNTs on the SiC Matrix. The SiC matrix would crack owing to the mismatch of coefficients of thermal expansion [27] between carbon fibers and SiC matrix and the shrinkage of $\mathrm{SiC}$ matrix during high-temperature pyrolysis, leading to thermal physical injury of fibers. To study the influence of CNTs on the matrix during high-temperature pyrolysis, the morphologies of the composites after the first cycle of PIP are observed. Big cracks can be found and matrix breaks up completely in Figure 2(a). However, cracks become smaller and matrix remains monolithic except for the partial divorces (Figure 2(b)) when introducing $1 \mathrm{wt} \% \mathrm{CNTs}$. As seen in Figure 2(c), broken CNTs far away from the crack tip are straightened and tapered, similar to the "sword-insheath" failure behavior observed in MCNTs under tensile load [28], while CNTs near the crack tip are still integrated. Meanwhile, the morphologies of CNTs are different from the entangled twisted CNTs. The results indicate that the driving force to crack propagation can be consumed by the destruction of CNTs. The thermal damage on carbon fibers can also be suppressed by reducing the direct contact between carbon fibers to $\mathrm{SiC}$ matrix. Thus, CNTs could guarantee the properties of the prepared composites, effectively.

Specific properties of the as-fabricated composites are given in Table 1 . The densities of $\mathrm{C}_{\mathrm{f}} / \mathrm{SiC}$ and $\mathrm{C}_{\mathrm{f}} / 1 \% \mathrm{CNTs} / \mathrm{SiC}$ are exactly alike, $1.61 \mathrm{~g} / \mathrm{cm}^{3}$, and small to the reported [13, 15 ], resulting from the relatively high fiber volume fraction of the fabrics and the low density of CNTs $\left(1.74 \mathrm{~g} / \mathrm{cm}^{3}\right)$ [29]. However, the density of $\mathrm{C}_{\mathrm{f}} / 2.5 \% \mathrm{CNTs} / \mathrm{SiC}$ decreases significantly, caused by the potential negative influence of excess CNTs. The change regulation of ILSS and the flexural strength correspond to those of the densities. Moderate CNTs can improve ILSS and the flexural strength to some extent, 


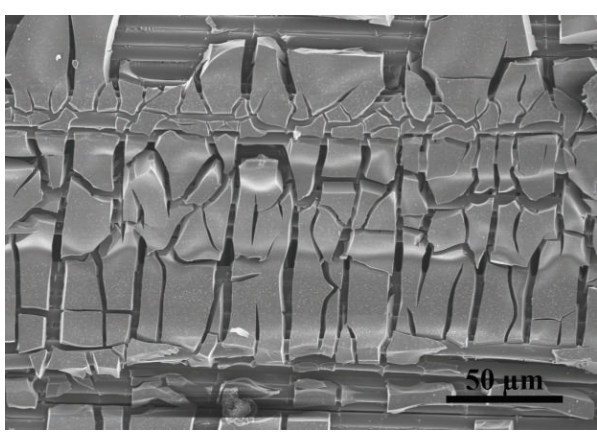

(a)

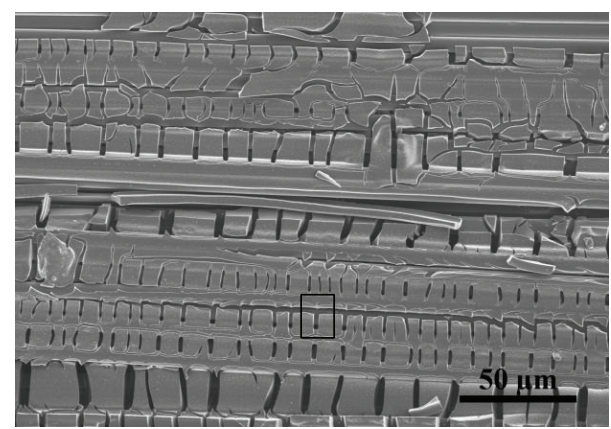

(b)

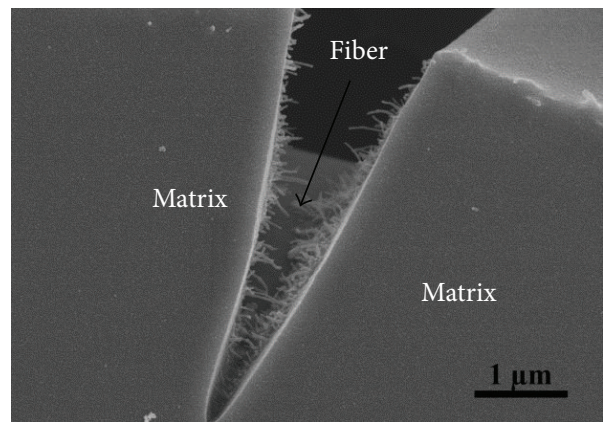

(c)

FIgURE 2: SEM images of the matrix morphologies on fibers after the first cycle of PIP of (a) $\mathrm{C}_{\mathrm{f}} / \mathrm{SiC}$, (b) $\mathrm{C}_{\mathrm{f}} / 1 \% \mathrm{CNTs} / \mathrm{SiC}$, and (c) magnifying image of the crack in the composite of $\mathrm{C}_{\mathrm{f}} / 1 \% \mathrm{CNTs} / \mathrm{SiC}$.

TABLE 1: Physical and mechanical properties of $\mathrm{C}_{\mathrm{f}} / \mathrm{SiC}, \mathrm{C}_{\mathrm{f}} / 1 \% \mathrm{CNTs} / \mathrm{SiC}$, and $\mathrm{C}_{\mathrm{f}} / 2.5 \% \mathrm{CNTs} / \mathrm{SiC}$.

\begin{tabular}{lcccc}
\hline Composites & Density $\left(\mathrm{g} / \mathrm{cm}^{3}\right)$ & Porosity $(\%)$ & ILSS $(\mathrm{MPa})$ & Flexural strength $(\mathrm{MPa})$ \\
\hline $\mathrm{C}_{\mathrm{f}} / \mathrm{SiC}$ & $1.61 \pm 0.02$ & $8.30 \pm 0.49$ & $14.11 \pm 2.10$ & $286.16 \pm 33.86$ \\
$\mathrm{C}_{\mathrm{f}} / 1 \% \mathrm{CNTs} / \mathrm{SiC}$ & $1.62 \pm 0.01$ & $8.36 \pm 0.79$ & $18.58 \pm 2.70$ & $365.25 \pm 15.39$ \\
$\mathrm{C}_{\mathrm{f}} / 2.5 \% \mathrm{CNTs} / \mathrm{SiC}$ & $1.55 \pm 0.01$ & $10.03 \pm 0.77$ & $14.14 \pm 1.33$ & $210.14 \pm 14.03$ \\
\hline
\end{tabular}

while excess CNTs play a negative effect due to the insufficient impregnation of the precursor. And detailed mechanism of action would be given in the following.

3.3. The Influence of the Content of CNTs on ILSS. ILSS of the as-fabricated composites is small to the reported [17] due to the relatively weak interfacial strength stemming from the smooth surface of T700SC carbon fiber [30]. However, with the introduction of $1 \mathrm{wt} \% \mathrm{CNTs}$, the smooth surface of T700SC became uneven and ILSS was improved by $31 \%$ finally. SEM images of the fracture surface of composites that failed in shear are shown in Figure 3. In the composite of $\mathrm{C}_{\mathrm{f}} / \mathrm{SiC}$, vivid gaps between $\mathrm{SiC}$ matrix and carbon fiber can be observed, as shown in the rectangular area in Figure 3(a). Furthermore, the surface of fibers is smooth with little residual matrix, indicating poor interfacial strength. This is not the case when introducing $1 \mathrm{wt} \% \mathrm{CNTs}$ via freeze-drying method. As shown in Figure 3(b), there is no gap and lots of CNTs adhere to the fibers, indicating that a strong interfacial strength exists. In addition, the $\mathrm{SiC}$ matrix is dense and there is no obvious defect for the reason that $1 \mathrm{wt} \% \mathrm{CNTs}$ does not hinder the precursor impregnation owing to the existing nanopores between fibers and nonclosed structure of CNT sheets. However, as in Figure 3(c), pores with the size of several hundred nanometers can be clearly seen in the matrix (black arrow) when increasing the CNT content to $2.5 \mathrm{wt} \%$, further. The formation of obvious defects could be attributed to the strong diffusion resistance from thicker CNT sheets, approximate-closed CNT cell structure, and dense CNT networks between fibers. Though it was beneficial to improve ILSS between the SiC matrix and fibers by increasing the CNT content [16], the accompanying defects would reduce ILSS. After all, ILSS was affected by the interfacial strength and properties of the matrix $[31,32]$. As a result of the two factors, ILSS of $\mathrm{C}_{\mathrm{f}} / 2.5 \% \mathrm{CNTs} / \mathrm{SiC}$ was improved indistinctively. In brief, it is necessary to choose an optimal CNT content to achieve high-performance $\mathrm{C}_{\mathrm{f}} / \mathrm{CNTs} / \mathrm{SiC}$ composites.

3.4. The Flexural Strength of As-Fabricated Composites. The flexural strength of $\mathrm{C}_{\mathrm{f}} / \mathrm{SiC}$ was improved by $27 \%$ through 


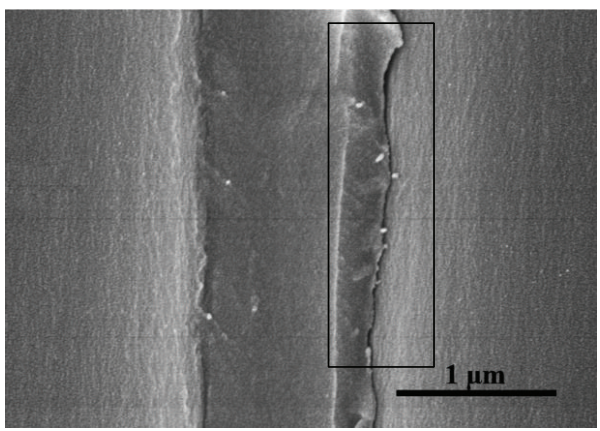

(a)

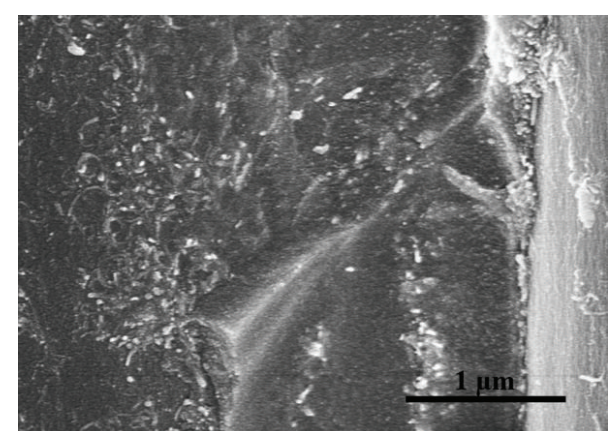

(b)

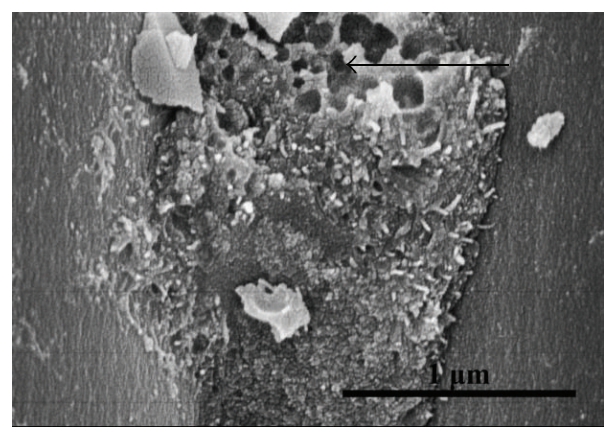

(c)

Figure 3: SEM images of the fracture surface of composites that failed in shear of (a) $\mathrm{C}_{\mathrm{f}} / \mathrm{SiC},(\mathrm{b}) \mathrm{C}_{\mathrm{f}} / 1 \% \mathrm{CNTs} / \mathrm{SiC}$, and (c) $\mathrm{C}_{\mathrm{f}} / 2.5 \% \mathrm{CNTs} / \mathrm{SiC}$.

$1 \mathrm{wt} \% \mathrm{CNTs}$, while the value of $\mathrm{C}_{\mathrm{f}} / 2.5 \% \mathrm{CNTs} / \mathrm{SiC}$ decreased. The fracture morphologies after test are given in Figure 4. Lots of fiber pull-out can be found in Figures 4(a), 4(c), and 4(e), indicating noncatastrophic failure modes happening due to relatively weak interfacial strength between fibers and $\mathrm{SiC}$ matrix. Nevertheless, the concrete fracture mechanisms are different. $\mathrm{C}_{\mathrm{f}} / 1 \% \mathrm{CNTs} / \mathrm{SiC}$ shows a "pull-out of short filaments" failure mode (Figure 4(c)) compared with the long pull-out of filaments of $\mathrm{C}_{\mathrm{f}} / \mathrm{SiC}$, indicating that CNTs effectively increase the interfacial strength and make the pull-out of fibers hard. The failure mode switches to "long filaments with fiber clusters" (Figure 4(e)) when the CNT content is increased to $2.5 \mathrm{wt} \%$. The fiber clusters (red circle region), originating from the strong interfacial strength because of CNTs, fracture brittlely with the pull-out of few fibers. To study the fracture mechanisms further, the features of typical fracture region around the fibers are observed. The major fracture mode of $\mathrm{C}_{\mathrm{f}} / \mathrm{SiC}$ is ductile, although some fibers fracture brittlely. Little matrix adheres to fibers, and the surface of matrix debonding from fibers (Figure 4(b)) is smooth and intact (red rectangular region), suggesting a relatively poor interfacial strength that would lead to invalid load transfer [30]. However, the interfacial strength is reinforced by CNTs (red circles) when introducing $1 \mathrm{wt} \% \mathrm{CNTs}$ in the composites (Figure 4(d)), consistent with literature reports $[14,16]$. CNTs in the matrix inhibit the crack initiation (the inset) and force the crack to deflect (black curve). Both mechanisms consume energy and inhibit the crack propagation. In consideration of alleviating the thermal stress and protecting fibers in the previous analysis, the property of $\mathrm{C}_{\mathrm{f}} / 1 \% \mathrm{CNTs} / \mathrm{SiC}$ is improved. And the interfacial strength between $\mathrm{SiC}$ matrix and carbon fibers is further enhanced by increasing the content of CNTs to $2.5 \mathrm{wt} \%$. The surface of the matrix becomes rugged and coarse (red rectangular region) after the matrix debonds from the fibers in the cluster, and it is demonstrated that $\mathrm{SiC}$ matrix is destroyed during the pullout of fibers. Thus, it can be concluded that there is a stronger interfacial strength than that of $\mathrm{C}_{\mathrm{f}} / 1 \% \mathrm{CNTs} / \mathrm{SiC}$ owing to the increment of the CNT content. Nevertheless, excess CNTs lead to impeding the precursor impregnation and the matrix thus is full of defects (red arrow). The nanopores make the property of $\mathrm{C}_{\mathrm{f}} / 2.5 \% \mathrm{CNTs} / \mathrm{SiC}$ decrease obviously. Therefore, it is clear that an appropriate content of CNTs is crucial and the concentration of $1 \mathrm{wt} \%$ of CNTs is beneficial to the property of the composites.

\section{Conclusions}

Firstly, $\mathrm{C}_{\mathrm{f}} / \mathrm{CNTs} / \mathrm{SiC}$ composites were prepared via PIP process assisted by freeze-drying method. Secondly, the weak interfacial strength between T700SC carbon fibers and SiC matrix has been handled effectively. Thirdly, the continuous CNT networks with nanopores of $\sim 200 \mathrm{~nm}$ play a crucial role in reinforcing the interfacial strength. Compared with the composites without CNTs, ILSS and the flexural strength of $\mathrm{C}_{\mathrm{f}} / 1 \% \mathrm{CNTs} / \mathrm{SiC}$ were increased by $31 \%$ and $27 \%$, respectively. However, excess CNTs would play a negative effect. 


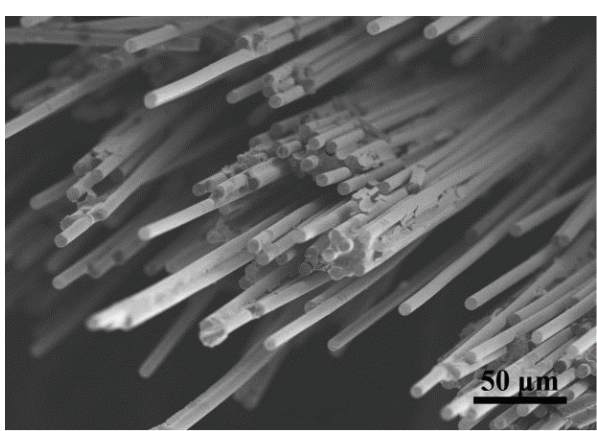

(a)

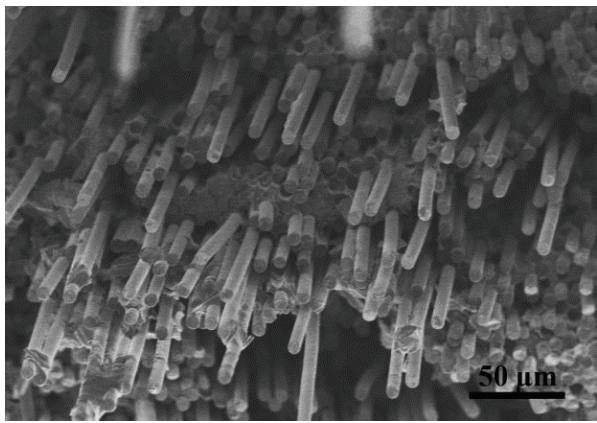

(c)

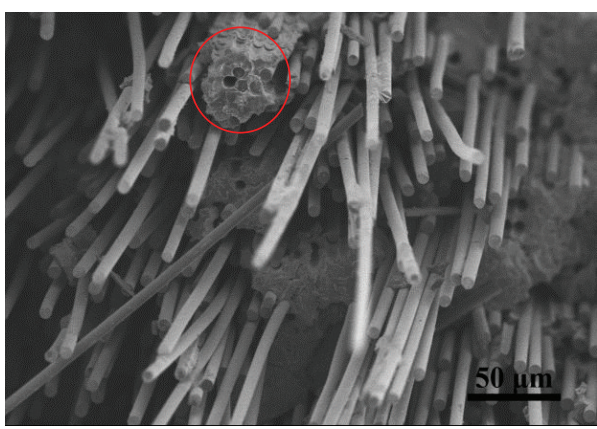

(e)

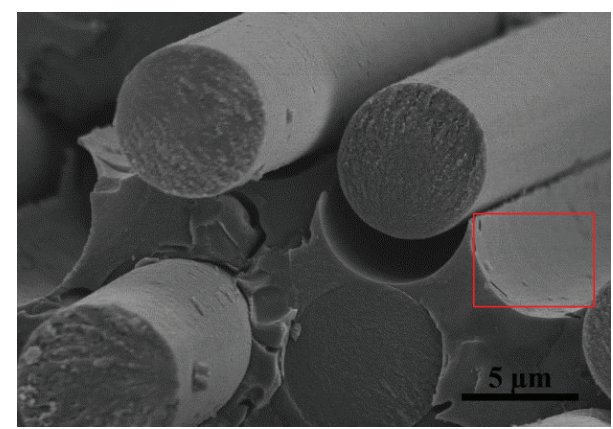

(b)

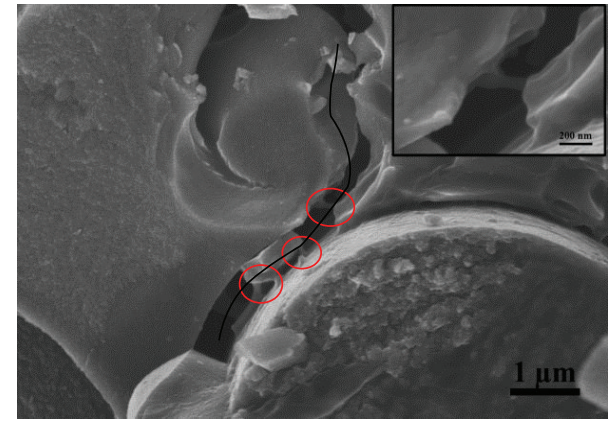

(d)

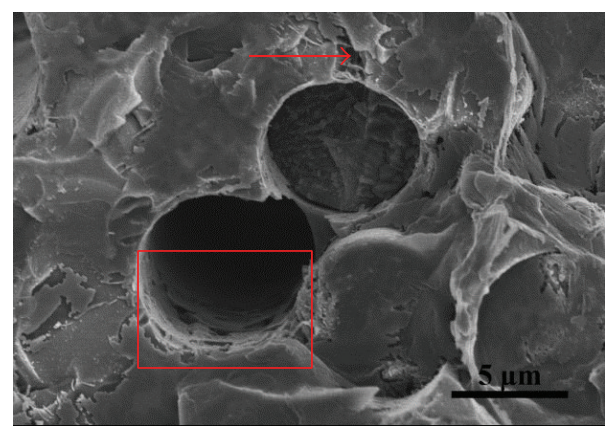

(f)

Figure 4: SEM images of the fracture morphologies after three-point bending test of (a) (b) $\mathrm{C}_{\mathrm{f}} / \mathrm{SiC}$, (c) (d) $\mathrm{C}_{\mathrm{f}} / 1 \% \mathrm{CNTs} / \mathrm{SiC}$, and (e) (f) $\mathrm{C}_{\mathrm{f}} / 2.5 \% \mathrm{CNTs} / \mathrm{SiC}$.

\section{Conflict of Interests}

The authors declare that there is no conflict of interests regarding the publication of this paper.

\section{Acknowledgments}

This work was supported by funding from the National Natural Science Fund Program of China (Grant no. 51072130) and the Natural Science Fund Program of Tianjin (Grant no. 14JCYBJC17300).

\section{References}

[1] J. Llorca and R. N. Singh, "Influence of fiber and interfacial properties on fracture behavior of fiber-reinforced ceramic composites," Journal of the American Ceramic Society, vol. 74, no. 11, pp. 2882-2890, 1991.
[2] L. Filipuzzi, G. Camus, R. Naslain, and J. Thebault, "Oxidation mechanisms and kinetics of $1 \mathrm{D}-\mathrm{SiC} / \mathrm{C} / \mathrm{SiC}$ composite materials: I, An experimental approach," Journal of the American Ceramic Society, vol. 77, no. 2, pp. 459-466, 1994.

[3] R. L. Dong, Y. Hirata, H. Sueyoshi, M. Higo, and Y. Uemura, "Polymer impregnation and pyrolysis (PIP) method for the preparation of laminated woven fabric/mullite matrix composites with pseudoductility," Journal of the European Ceramic Society, vol. 24, no. 1, pp. 53-64, 2004.

[4] J. Magnant, R. Pailler, Y. Le Petitcorps et al., "Fiber-reinforced ceramic matrix composites processed by a hybrid technique based on chemical vapor infiltration, slurry impregnation and spark plasma sintering," Journal of the European Ceramic Society, vol. 33, no. 1, pp. 181-190, 2013.

[5] H. Mei, H. Q. Li, Q. L. Bai, Q. Zhang, and L. F. Cheng, "Increasing the strength and toughness of a carbon fiber/silicon carbide composite by heat treatment," Carbon, vol. 54, pp. 4247, 2013. 
[6] R. Naslain, A. Guette, F. Rebillat, R. Pailler, F. Langlais, and X. Bourrat, "Boron-bearing species in ceramic matrix composites for long-term aerospace applications," Journal of Solid State Chemistry, vol. 177, no. 2, pp. 449-456, 2004.

[7] S. Schmidt, S. Beyer, H. Knabe, H. Immich, R. Meistring, and A. Gessler, "Advanced ceramic matrix composite materials for current and future propulsion technology applications," Acta Astronautica, vol. 55, pp. 409-420, 2004.

[8] W. Yang, H. Araki, A. Kohyama, S. Thaveethavorn, H. Suzuki, and T. Noda, "Process and mechanical properties of in situ silicon carbide-nanowire-reinforced chemical vapor infiltrated silicon carbide/silicon carbide composite," Journal of the American Ceramic Society, vol. 87, no. 9, pp. 1720-1725, 2004.

[9] J.-C. Charlier, T. W. Ebbesen, and P. Lambin, "Structural and electronic properties of pentagon-heptagon pair defects in carbon nanotubes," Physical Review B, vol. 53, no. 16, pp. 1110811113, 1996.

[10] M. M. J. Treacy, T. W. Ebbesen, and J. M. Gibson, "Exceptionally high Young's modulus observed for individual carbon nanotubes," Nature, vol. 381, no. 6584, pp. 678-680, 1996.

[11] M. A. Osman and D. Srivastava, "Temperature dependence of the thermal conductivity of single-wall carbon nanotubes," Nanotechnology, vol. 12, no. 1, pp. 21-24, 2001.

[12] H. Z. Wang, X. D. Li, J. Ma, G. Y. Li, and T. J. Hu, "Fabrication of multi-walled carbon nanotube-reinforced carbon fiber/silicon carbide composites by polymer infiltration and pyrolysis process," Composites Science and Technology, vol. 72, no. 3, pp. 461466, 2012.

[13] H. Yu, X. Zhou, W. Zhang, H. Peng, C. Zhang, and K. Sun, "Properties of carbon nano-tubes- $\mathrm{C}_{\mathrm{f}} / \mathrm{SiC}$ composite by precursor infiltration and pyrolysis process," Materials \& Design, vol. 32, no. 6, pp. 3516-3520, 2011.

[14] J. Hu, S. Dong, X. Zhang et al., "Process and mechanical properties of carbon/carbon-silicon carbide composite reinforced with carbon nanotubes grown in situ," Composites Part A: Applied Science and Manufacturing, vol. 48, no. 1, pp. 73-81, 2013.

[15] J. B. Hu, S. M. Dong, Q. Feng, M. Y. Zhou, X. J. Wang, and Y. B. Cheng, "Tailoring carbon nanotube/matrix interface to optimize mechanical properties of multiscale composites," Carbon, vol. 69, pp. 621-625, 2014.

[16] Z. Hu, S. Dong, J. Hu, and B. Lu, "Fabrication and properties analysis of Cf-CNT/SiC composite," Ceramics International, vol. 39, no. 2, pp. 2147-2152, 2013.

[17] K. Sun, J. S. Yu, C. R. Zhang, and X. G. Zhou, "In situ growth carbon nanotube reinforced $\mathrm{SiC}_{\mathrm{f}} / \mathrm{SiC}$ composite," Materials Letters, vol. 66, no. 1, pp. 92-95, 2012.

[18] S. P. Sharma and S. C. Lakkad, "Effect of CNTs growth on carbon fibers on the tensile strength of CNTs grown carbon fiber-reinforced polymer matrix composites," Composites Part A: Applied Science and Manufacturing, vol. 42, no. 1, pp. 8-15, 2011.

[19] L. Dong, Y. Li, L. Wang, F. Hou, and J. Liu, "Spatial dispersion state of carbon nanotubes in freeze-drying method prepared carbon fiber based preform and its effect on electrical conductivity of carbon fiber/epoxy composite," Materials Letters, vol. 130, pp. 292-295, 2014.

[20] L. Dong, Y. Li, L. Wang, Z. Wan, F. Hou, and J. Liu, "Combination effect of physical drying with chemical characteristic of carbon nanotubes on through-thickness properties of carbon fiber/epoxy composites," Journal of Materials Science, vol. 49, no. 14, pp. 4979-4988, 2014.
[21] L. Dong, F. Hou, Y. Li, L. Wang, H. Gao, and Y. Tang, "Preparation of continuous carbon nanotube networks in carbon fiber/epoxy composite," Composites Part A: Applied Science and Manufacturing, vol. 56, pp. 248-255, 2014.

[22] W. L. Li, K. Lu, and J. Y. Walz, "Freeze casting of porous materials: review of critical factors in microstructure evolution," International Materials Reviews, vol. 57, no. 1, pp. 37-60, 2012.

[23] M. C. Gutierrez, M. J. Hortiguela, J. M. Amarilla, R. Jimenez, M. L. Ferrer, and F. del Monte, "Macroporous 3D architectures of self-assembled MWCNT surface decorated with Pt nanoparticles as anodes for a direct methanol fuel cell," Journal of Physical Chemistry C, vol. 111, no. 15, pp. 5557-5560, 2007.

[24] S.-H. Park, K.-H. Kim, K. C. Roh, and K.-B. Kim, "Morphology control of three-dimensional carbon nanotube macrostructures fabricated using ice-templating method," Journal of Porous Materials, vol. 20, no. 5, pp. 1289-1297, 2013.

[25] W. Li, D. Long, J. Miyawaki et al., "Structural features of polyacrylonitrile-based carbon fibers," Journal of Materials Science, vol. 47, no. 2, pp. 919-928, 2012.

[26] M. C. Gutiérrez, M. L. Ferrer, and F. del Monte, "Ice-templated materials: sophisticated structures exhibiting enhanced functionalities obtained after unidirectional freezing and icesegregation-induced self-assembly," Chemistry of Materials, vol. 20, no. 3, pp. 634-648, 2008.

[27] Z. C. Li, X. G. Yin, T. Ma, W. Miao, and Z. J. Zhang, "Bending and thermal expansion properties of $2.5 \mathrm{D} \mathrm{C} / \mathrm{SiC}$ composites," Materials Transactions, vol. 52, no. 12, pp. 2165-2167, 2011.

[28] M.-F. Yu, O. Lourie, M. J. Dyer, K. Moloni, T. F. Kelly, and R. S. Ruoff, "Strength and breaking mechanism of multiwalled carbon nanotubes under tensile load," Science, vol. 287, no. 5453, pp. 637-640, 2000.

[29] S. H. Kim, G. W. Mulholland, and M. R. Zachariah, "Density measurement of size selected multiwalled carbon nanotubes by mobility-mass characterization," Carbon, vol. 47, no. 5, pp. 12971302, 2009.

[30] B. Li, C. R. Zhang, F. Cao, S. Q. Wang, B. Chen, and J. S. Li, "Effects of fiber surface treatments on mechanical properties of T700 carbon fiber reinforced $\mathrm{BN}-\mathrm{Si}_{3} \mathrm{~N}_{4}$ composites," Materials Science and Engineering A, vol. 471, no. 1-2, pp. 169-173, 2007.

[31] D. C. Davis, J. W. Wilkerson, J. Zhu, and D. O. O. Ayewah, "Improvements in mechanical properties of a carbon fiber epoxy composite using nanotube science and technology," Composite Structures, vol. 92, no. 11, pp. 2653-2662, 2010.

[32] C. Ren, Q. Gong, L. Guo, X. Zhao, and J. Liang, "Analyses of reinforcing effects of in situ grown CNTs on carbon fibre fabric/epoxy composites at micro- and macroscale," Micro \& Nano Letters, vol. 7, no. 3, pp. 240-243, 2012. 

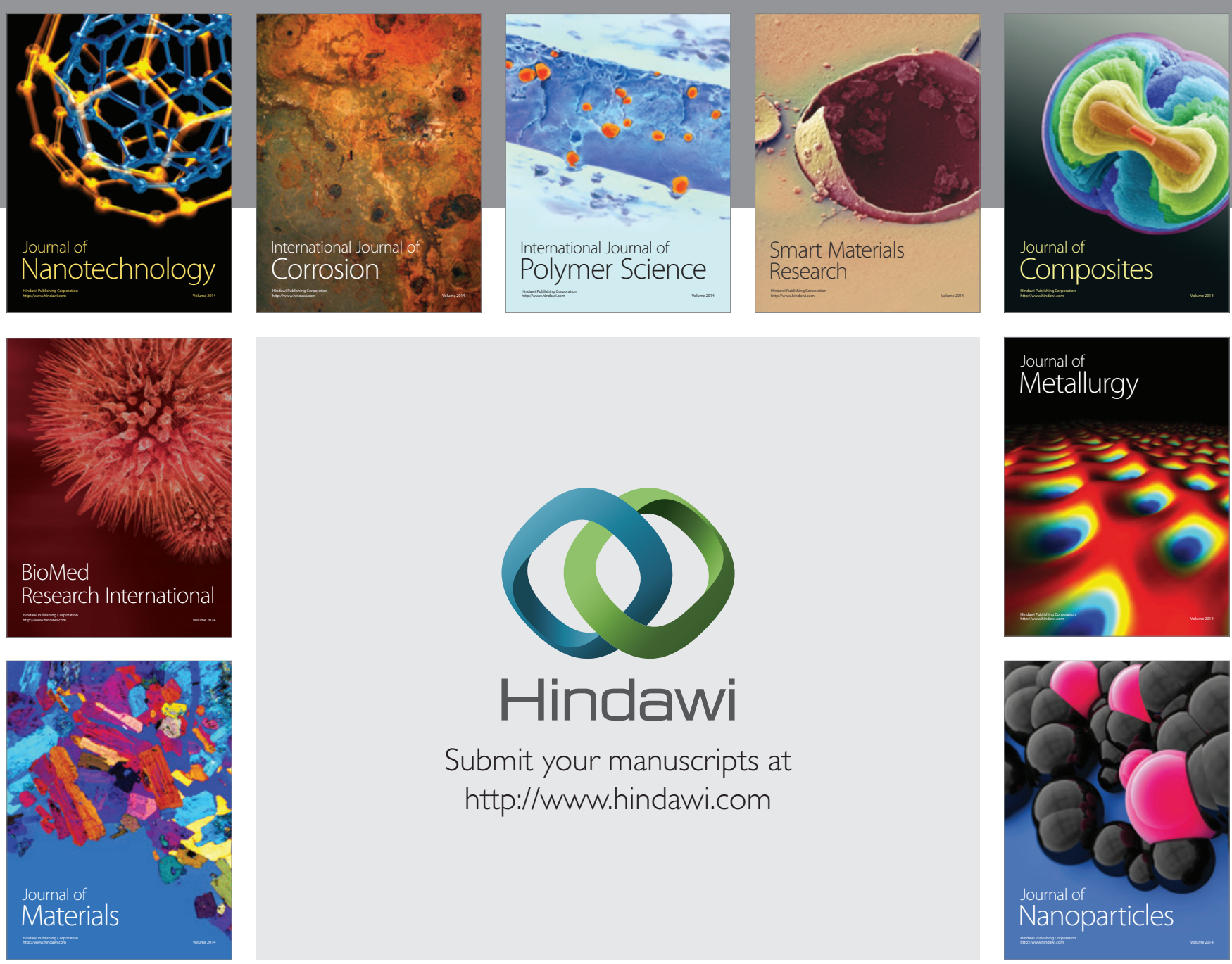

Submit your manuscripts at http://www.hindawi.com
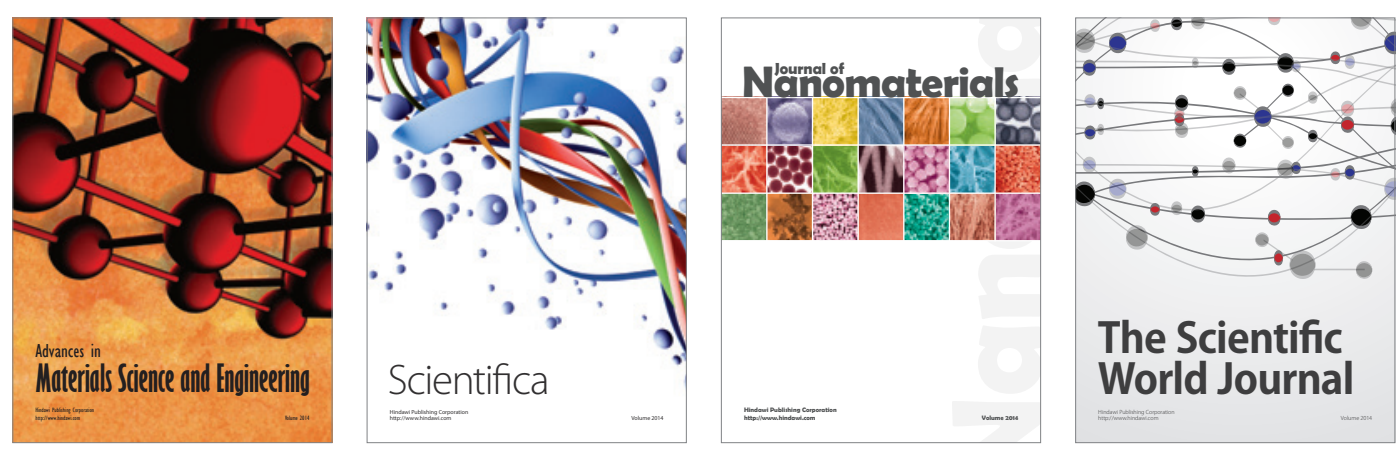

\section{The Scientific World Journal}
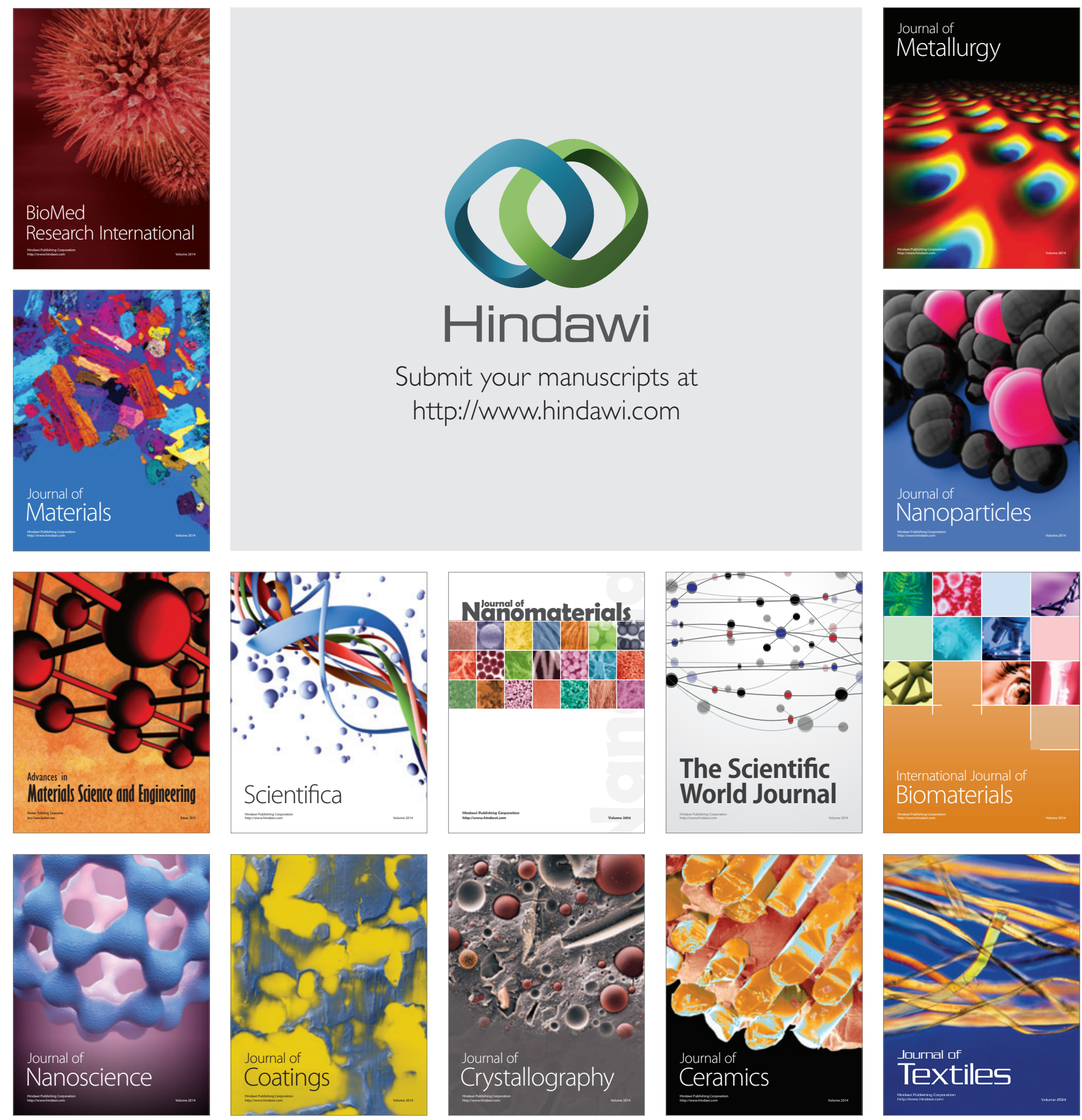